\title{
The Determinants of Quality in Accounting Information System: A Case of SMEs in Sibu Sarawak
}

\author{
Tracy Yiin Yien*1, Nicholas Lim Kuan Hon ${ }^{1}$, Jessica Lyn Andam ${ }^{2}$ and Maximus Balla \\ Tang $^{3}$ \\ ${ }^{1}$ School of Business and Management, UCSI University \\ ${ }^{2}$ Department of Business Management, Methodist Pilley Institute (MPI) \\ ${ }^{3}$ Centre of University Courses and Innovative Learning, University College of \\ Technology Sarawak (UCTS) \\ *Corresponding author: tyyien0413@gmail.com
}

\begin{abstract}
Accounting Information System (AIS) plays a vital role in enhancing the effectiveness of business operations and the quality of management or investors' decision-making. The quality of AIS is of concerned by many parties including management, investors, auditors and so forth. Quality of AIS will affects the reliability of the accounting information within an organization. Hence, this study was implemented to investigate the relationship of determinants (Management commitment, Knowledge management, User or employees' training, and Organizational culture) toward the quality of AIS among Small and Medium-sized Enterprises (SMEs) in Sibu, Sarawak. The primary data was collected via questionnaire method disseminated using Google Form. The population of this case study were accountants or managers from SMEs located in Sibu, Sarawak. The sample size was 142 which selected via random sampling method. The finding of the study indicates that management commitment and user or employees' training had positive impact on the quality of AIS. This study is helpful in gaining a greater understanding of the determinants that will affect the quality of AIS among SMEs in Sibu. Furthermore, the study provides related parties such as management, novice users and auditors a better insight into the AIS implementation and quality in Sibu, Sarawak. Finally, the case study will give related parties a clear direction to implement effective efforts in improving the AIS quality.
\end{abstract}

Keywords: Accounting Information System (AIS), Small and Medium-Sized Enterprises (SMEs), Management Commitment, Knowledge Management, User/ Employees' Training, Organizational Culture

\section{Introduction}

Nowadays, globalization strategy is adopted by majority of companies around the globe. Information technology has a strong influence in all aspects of life, economy, and society (Thuan, 2019). Therefore, there is a need for these companies to further improve their flexibility, increase the quality of the product as well as achieve timeliness and costeffectiveness to achieve their business goal (Hunter \& Long, 2003). Besides, the importance of information is vital for the sustainability of companies due to the rise of the knowledge-based economy (Guinea, Kelley, \& Hunter, 2005). Business practices and strategy of companies has also been revolutionized by Information Technology (IT). Accountancy is important for organization because it directly influences decisionmaking (Bergant, 2021). Thus, an effective Information System (IS), especially an AIS 
is crucial to meet the requirements of companies in this globalization era (Mitchell, Reid, \& Smith, 2000).

AIS is a system that can collect data, process procedures and further yield useful financial information for the users of financial statements in the decisions making process (Romney \& Steinbart, 2015). It is an operating system that integrates the Theory of IT and Accounting to help the company in managing and controlling business performance. AIS enables an organization to convert accounting data into information that is important to support decision making (Clearly, 2017). AIS aims to simplify and accelerate the data processing to produce relevant financial reports for managerial decision making (Rosa \& Purfini, 2019). According to Kanakriyah (2016), AIS provides important information for all related parties within an organization. The implementation of AIS is vital for both SMEs and larger enterprises to gather and process the information in a competitive environment (Louadi, 2009). Therefore, managers need to develop a strategy to improve their data processing capabilities by enhancing the quality of AIS to satisfy their demand for information (Ta \& Nguyen, 2020).

The flexibility nature of SMEs allows it responding to new opportunities through evaluating the trend of the economy in a competitive environment (Louadi, 2009). However, most people neglected the characteristic of SMEs when developing the business strategy, and this will cause some problems in the application of AIS (Nguyen $\&$ Nguyen, 2020). Therefore, the strategy of AIS adoption in large businesses may not suitable to be applied in SMEs. Most of the SMEs in Malaysia have implemented AIS, but AIS is not being utilized effectively to perform its functions. Computerized AIS is rarely used among SMEs of Malaysia, so it is not enough to generate important indicators about the financial performance of the company (Nguyen \& Nguyen, 2020).

The same scenario occurs in Sibu, Sarawak in which the implementation of AIS is ineffective especially in SMEs. According to Ambarwati, Firdaus, \& Widaninggar (2020), human behavior in organizations impact the success rate of AIS implementation. One of the main reasons is the lack of awareness on the importance of AIS among managers of SMEs. Support from top management significantly affects the success of AIS implementation (Shagari, Abdullah, \& Saat, 2017). Therefore, the commitment from top management or owner of SMEs to implement effective AIS is lacking. The practice of some SMEs in Sibu is using Microsoft Excel to record their daily business transactions. Some of them only use AIS to record transaction data. This means that the AIS is not fully utilized to its full potential due to many factors. Thus, the accounting or transaction data cannot be process further into more useful financial information for SMEs to make business decisions. This study was conducted to close the gaps in the determinants of the quality of AIS by recognizing the factors that will affect its quality.

There are plenty of studies in the area of AIS that have been carried out by scholars. However, different geographic locations posed different factors that might affect the determinants of quality in AIS. Thus, more researches on investigating the factors affecting the quality of AIS should be carried out to supplement the empirical evidence on this issue (Nguyen \& Nguyen, 2020). The general objective of this study is to investigate the relationship of the determinants towards the quality of AIS among SMEs in Sibu, Sarawak. The investigated determinants of this study were management commitment, knowledge management, user or employees' training and organizational culture. 


\section{Literature Review}

\section{Quality of AIS}

AIS is an IS that is designed and developed to achieve certain accounting, economic, and financial tasks. AIS assembles, stores, and processes financial data or resources using specific procedures to produce necessary financial information for its users to make their business decisions throughout all organizational levels (Agung, 2015). Onaolapo and Odetayo (2012) indicate that a good AIS helps the entities to improve organizational effectiveness and performance by evaluating their past results and to plan future goals using the information analyzed and provided by AIS. This means that the AIS quality will significantly affect all stakeholders such as employees, management and so forth in making accurate and good decisions (Nurhidayati, Sensuse, \& Noprisson, 2017). Therefore, the quality of AIS can be interpreted as the evaluation of its ability in providing useful outcomes that reach the decision-makers' information demands. The quality of AIS can be assessed by its effects on accounting information quality, the effectiveness of internal controls, the enhancement of decision-making procedures and assessment of business performances (Nguyen \& Nguyen, 2020). Without quality AIS, there will be no high-quality accounting information.

\section{Management Commitment}

Management commitment is the level of confidence and acceptance of top and middle management continuously involve and cooperate in the process of identifying and formulating the employment objectives, the accountability level, and the performance commitments (Fitrios, 2016). Management commitment can be summarized as "engaging in and maintaining behaviors that others achieve the goals" (Al-Hiyari, AlMashregy, Mat, \& Alekam, 2013). Rahayu (2012) states that the most important determinant in the development and improvement of a firm's IS was the management's support and on-going commitment. Thus, the implementation of an IS without management commitment will fail (Tilahun, 2019). This is because the company's management generally acts as a dominant and essential role in any system improvement and development process such as design the IS development plan, implement system reviews and so forth (Meiryani, 2014). When the management gives serious attention to the implementation of the IS, the quality of system can be significantly enhanced with the positive commitment of management (Ta \& Nguyen, 2020).

\section{Knowledge Management}

Knowledge management is defined as a series of practices aimed at discovering and utilizing organizational knowledge resources (Bateman \& Snell, 2004). It is a very important managerial tool that can increase the value of the organization by utilizing intellectual resources (Campos \& Pablos, 2004). It helps the organizations to identify, organize and transmit unstructured organizational information and skills (Turban, Leidner, McLean, \& Wetherbe, 2004). The purpose of knowledge management is to provide a better knowledge practice, establish a better organizational behavior and culture as well as make a better decision to achieve better organizational performance by increasing organizational knowledge (King, 2009). Knowledge management is also considered as a part of an enterprise system that can be integrated with the AIS within an organization. Therefore, the knowledge management capabilities possess a positive relationship with the quality of an enterprise's AIS (Sedera \& Gable, 2010). 


\section{User or Employees' Training}

Training is the program of acquiring and improving employee skills and knowledge for their performance (Rue \& Byars, 2007). Employees are required to participate in the training program to be familiarize with the application of the company rules and improve their skills to complete their tasks. Training can include improving employee skills and knowledge that are related to any general, interpersonal, technical, and problem-solving skills in the operating accounting system (Wisna, 2018). Moreover, they will also understand the severity and limitations of AIS when performing their task. According to Diansari, Sujana, Budiasih and Sari (2020), it shows that users of AIS will increase knowledge and improve performance skills after attending training sessions frequently or , thereby it could minimize errors when operating AIS applications. If the training programs are instructed by experts, users can be benefited to promote daily work and increase creativity in using AIS. Therefore, the research has shown that training and education own a positive relationship with the performance of AIS. The higher level of training and education of users, the higher the performance of AIS.

\section{Organizational Culture}

Organizational culture is recognized as the system of shared beliefs, actions, principles, norms, artifacts, and values that are developed within a company and directs the employees' behaviors (Endraria, 2018). Nguyen and Nguyen (2020) asserted that organizational culture influences the AIS's quality as it determines the organizational members' attitudes, behaviors, responsibilities, as well serving as the benchmark in each program that is controlled by the company. Organizational culture can be considered as an origin of strength or otherwise a significant barrier against any system development at the same time (Aldegis, 2018). Any massive development or alterations in the company's computerized IS might require employees and management to push themselves to adapt to the new changes. Some companies with weak organizational culture might resist change but some with strong culture might accept and adapt to the development quickly. A good AIS cannot be carried out if it is not supported by a strong or increased organizational culture and thus the system quality may not be guaranteed (Nusa, 2015).

\section{Technological Changes and Quality of AIS}

In recent years, companies had tried to keep accounting practices pace with the rapid adoption of technology. According to Bong and Susanto (2018), information technology is one of the determinants that can increase the quality of AIS. A large set of business transactions, the advent of Enterprise Resource Planning, and automated control systems had accelerated the need to integrate analysis and information technology into accounting practice. According to Algrari and Ahmed (2019), AIS should be updated in accordance to the technological development. Accounting manual is a cumbersome practice, so accountants often make some errors carelessly and this causes substantive issues of asymmetry and discrepancy. Accountants also need to spend a lot of time and energy in verifying calculations and reconciliations, thereby affecting their working efficiency. User's competence in the application of technology affects the quality of accounting information systems (Endraria, 2016). Then, these problems had been solved by introducing basic spreadsheet software with computer powers. However, the diversification of society and the improvement of information processing make companies desire to have more complex needs on technology with more comprehensive 
functions. Rapid advancement of technology and globalization increase the need for the application of AIS (Abu-Raqabeh, 2018). With the evolution of technology, the skills of the accountants are required to expand in both scope and adaptability. For example, the job responsibilities of accountants are subsequently evolving from preparation of the financial information to making more explanations on financial results. The accounting standards for bookkeeping entries is also replaced by systemic understanding and concerns about data quality and security. It is showed that technology will continually change accountants' requisite competencies and redefine their roles. The quality of AIS will also be improved since AIS researchers has been establishing a more stable reporting and assurance environment in the accounting process with the adoption of technology (Krahel \& Vasarhelyi, 2014).

\section{Research Hypotheses}

The following hypotheses are developed to identify the causal relationships between independent variables (IVs) and dependent variable (DV).

H1: Management commitment has a positive relationship with the quality of AIS among SMEs in Sibu, Sarawak.

H2: Knowledge management has a positive relationship with the quality of AIS among SMEs in Sibu, Sarawak.

H3: User or employees' training has a positive relationship with the quality of AIS among SMEs in Sibu, Sarawak.

H4: Organizational culture has a positive relationship with the quality of AIS among SMEs in Sibu, Sarawak.

\section{Conceptual Framework of the Research}

\section{Independent Variables}

\section{Dependent Variable}

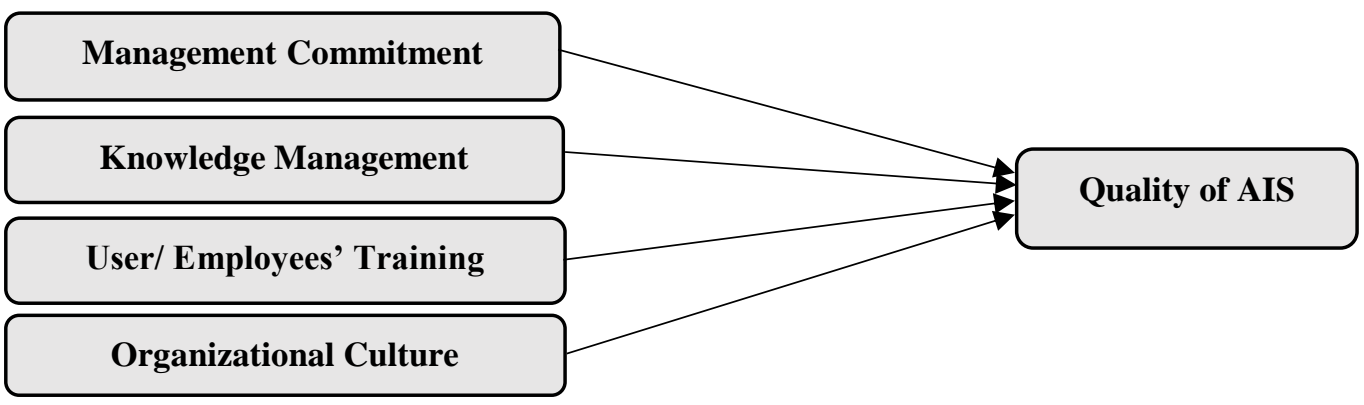

Figure 1: Conceptual Framework

Source: Fitrios (2016)

\section{Methodology}

The study focuses on the management and accounting personnel of SMEs in Sibu, Sarawak. However, the total target population for this study cannot be identified accurately since it is difficult to collect the total number of the management and accounting personnel of SMEs located in Sibu, Sarawak precisely. Thus, the guidelines provided by the study of Hair, Black, Babin, \& Anderson (2010) will be used. In this research, there were five constructs: management commitment, knowledge management, user or employees' training, organizational culture, and the quality of AIS. Each 
construct possesses five survey items. According to Hair et al. (2010), the minimum requirement for the sample size of this research is 125 respondents (five constructs times five items per construct times five respondents per item).

Random sampling technique was applied as a sampling method to gather the sample size of the study. Random sampling literally means selection of the sample randomly from a population, without any specific conditions. This was done by selecting sample from a list of SMEs located in Sibu, Sarawak. Calls were made to the listed SMEs to get their permission to conduct the survey and the questionnaire was distributed to candidates.

Statistical Package for the Social Sciences (SPSS) software version 22.0 was applied to examine as well as analyze the data gathered from the collected questionnaires. In this research, the Exploratory Factor Analysis (EFA), Reliability Analysis and Multiple Regression Analysis were applied to investigate the objective of the study. EFA was applied as it can be used to identify the smaller number of variables from the larger number of items obtained from the questionnaires (Yong \& Pearce, 2013).

Reliability analysis examines the level of internal consistency between various measurements of observed variables. Coefficient alpha $(\alpha)$ which is known as the most popular mechanism of measuring the reliability of a scale was applied in this study. The value of coefficient alpha that is between 0.60 and 0.70 shows an acceptable level of reliability. The value that is between 0.70 and 0.80 indicates a good level of reliability. An excellent level of reliability is shown when the value is between 0.80 and 0.95 . However, the value that is lower than 0.60 indicates a poor level of reliability (Zikmund, Babin, Carr, \& Griffin, 2011). A value that is greater than 0.95 might be an indication of redundancy (Ursachi, Horodnic \& Zait, 2015).

Multiple regression analysis is the dependence method that is used to measure the linear relationship between DV and IVs (Kumar, Talib, \& Ramayah, 2013). It attempts to forecast the value of DV based on the specific value of the IV. The regression coefficient expresses the relative importance of each IV in the prediction of the DV (Zikmund et al., 2011). IVs for this study were management commitment, knowledge management, user training, and organizational culture that can affect DV which is the quality of AIS. The variance in performance can be explained by these four IVs. The size of each regression coefficient indicates that the increase of one unit in IV will affect DV under the assumption of all other IVs remain unchanged. In addition, the individual correlation between the IV and DV was decomposed into the multiple $r$ or multiple correlation coefficient. The square of multiple $r, R$ Square $\left(R^{2}\right)$ is the amount of variance explained by the predictor variable in DV (Bougie \& Sekaran, 2009).

\section{Findings}

Table 1 Demographic Profile of Respondents (N=142)

\begin{tabular}{|l|l|c|c|}
\hline Demographic Variables & Categories & Frequency & Percentage (\%) \\
\hline Gender & Male & 47 & $33.1 \%$ \\
\hline & Female & 95 & $66.9 \%$ \\
\hline Age & Under 18 years old & 2 & $1.4 \%$ \\
\hline & 18 to 29 years old & 51 & $35.9 \%$ \\
\hline & 30 to 49 years old & 76 & $53.5 \%$ \\
\hline & 50 to 64 years old & 13 & $9.2 \%$ \\
\hline Ethnicity & 65 years old \& above & 0 & $0 \%$ \\
\hline & Malay & 2 & $1.4 \%$ \\
\hline & Chinese & 140 & $98.6 \%$ \\
\hline
\end{tabular}




Submitted: 5 April 2021 Accepted: 24 May 2021
\begin{tabular}{|l|l|c|c|}
\hline & Iban & 0 & $0 \%$ \\
\hline & Indian & 0 & $0 \%$ \\
\hline & Other & 0 & $0 \%$ \\
\hline Education Level & SPM & 56 & $39.4 \%$ \\
\hline & STPM / UEC & 11 & $7.7 \%$ \\
\hline & Diploma & 23 & $16.2 \%$ \\
\hline & Bachelor Degree & 41 & $28.9 \%$ \\
\hline & Master & 7 & $4.9 \%$ \\
\hline & Doctor of Philosophy & 0 & $0 \%$ \\
\hline Occupation & Other: ACCA & 4 & $2.8 \%$ \\
\hline Estimated Monthly Income & Management & 60 & $42.3 \%$ \\
\hline & Accounting Personnel & 82 & $57.7 \%$ \\
\hline & Below RM 1,800 & 57 & $40.1 \%$ \\
\hline & RM1,800 to RM 3,500 & 49 & $34.5 \%$ \\
\hline & RM3,501 or above & 36 & $25.4 \%$ \\
\hline
\end{tabular}

Source: Author

Table 1 demonstrates the demographic profile of respondents. 95 out of 142 (66.9\%) respondents are female whereas 47 out of 142 (33.1\%) respondents are male. Most of the respondents (76 persons or 53.5\%) are from age group of 30 to 49 years old, 51 out of $142(35.9 \%)$ respondents are from age group of 18 to 29 years old and $13(9.2 \%)$ respondents are from age group of 50 to 64 years old. The majority of respondents are Chinese, which accounted for 140 out of 142 (98.6\%) respondents while there are only $2(1.4 \%)$ respondents are Malay. The majority of respondents hold SPM (56 persons or $39.4 \%$ ), followed by Bachelor's Degree (41 persons or 28.9\%), Diploma (23 persons or $16.2 \%)$, STPM (11 persons or 7.7\%), Master (7 persons or $4.9 \%$ ) and Association of Chartered Certified Accountants (ACCA) (4 persons or 2.8\%). 60 (42.3\%) respondents' occupation are management whereas $82(57.7 \%)$ respondents are accounting personnel. 57 out of $142(40.1 \%)$ respondents' monthly income are below RM 1,800, followed by $49(34.5 \%)$ respondents whose monthly income are between RM1,800 and RM 3,500 and $36(25.4 \%)$ respondents whose monthly income are above RM 3,500.

Table 2 Factor Analysis

\begin{tabular}{|l|c|c|c|c|}
\hline \multirow{2}{*}{} & \multirow{2}{*}{ KMO } & \multicolumn{2}{|c|}{ Bartlett's Test of Sphericity } \\
\cline { 3 - 5 } & & $\begin{array}{c}\text { Approx. Chi- } \\
\text { Square }\end{array}$ & df & \multirow{2}{*}{ Sig. } \\
\hline Management Commitment & .809 & 212.784 & 10 & .000 \\
\hline Knowledge Management & .708 & 98.804 & 10 & .000 \\
\hline User or Employees' Training & .845 & 219.094 & 10 & .000 \\
\hline Organizational Culture & .741 & 148.804 & 10 & .000 \\
\hline Quality of AIS & .711 & 188.899 & 10 & .000 \\
\hline
\end{tabular}

Source: Author

Table 2 presents the results of Factor Analysis (FA) for IVs and DV. According to this table, Kaiser-Meyer-Olkin (KMO) values of all variables are ranged from 0.708 to 0.845 . The sig. values of all variables are 0.000 . 


\begin{tabular}{|l|l|c|c|}
\hline \multicolumn{2}{|c|}{ Variables } & $\begin{array}{c}\text { Numbers of Survey } \\
\text { Items }\end{array}$ & $\begin{array}{c}\text { Reliability } \\
(\boldsymbol{\alpha})\end{array}$ \\
\hline \multirow{3}{*}{$\begin{array}{l}\text { Independent } \\
\text { Variables (IVs) }\end{array}$} & Management Commitment & 5 & 0.808 \\
\cline { 2 - 4 } & Knowledge Management & 5 & 0.669 \\
\cline { 2 - 4 } & User or Employees' Training & 5 & 0.821 \\
\cline { 2 - 4 } & Organizational Culture & 5 & 0.728 \\
\hline $\begin{array}{l}\text { Dependent } \\
\text { Variable (DV) }\end{array}$ & Quality of AIS & 5 & 0.762 \\
\hline & Combined Scale & 25 & 0.916 \\
\hline
\end{tabular}

Source: Author

Table 3 indicates that the coefficient alpha of the variables ranged from 0.669 to 0.821 . This indicates that knowledge management (0.669) owns an acceptable level of internal consistency reliability and the remaining variables (0.728-0.821) possess a good level of internal consistency reliability. The overall degree of reliability can be deemed to be excellent since the value $(0.916)$ is between 0.80 and 0.95 .

Table 4 Multiple Regression Analysis

\begin{tabular}{|c|c|c|c|c|c|}
\hline & \multicolumn{5}{|c|}{ Quality of AIS } \\
\hline & B & Std. Error & Beta & Sig. & VIF \\
\hline Management Commitment & .310 & .088 & .314 & .001 & 1.769 \\
\hline Knowledge Management & .049 & .114 & .043 & .667 & 2.150 \\
\hline User or Employees' Training & .198 & .095 & .201 & .039 & 2.061 \\
\hline Organizational Culture & .168 & .095 & .172 & .079 & 2.092 \\
\hline $\mathbf{R}^{2}$ & \multicolumn{5}{|c|}{.380} \\
\hline Adjusted $\mathbf{R}^{2}$ & \multicolumn{5}{|c|}{.362} \\
\hline F-Statistics & \multicolumn{5}{|c|}{21.032} \\
\hline
\end{tabular}

Source: Author

The results derived using multiple regression analysis are indicated in Table 4. Management commitment has the highest Beta value (0.314). It is followed by user or employees' training (0.201), organizational culture (0.172) and knowledge management (0.043). The sig. values of these variables are ranged from 0.001 to 0.667 . All values of Variance Inflation Factor (VIF) are ranged from 1.769 to 2.150. Also, this table indicates that $\mathrm{R}^{2}$ value and $\mathrm{F}$-value are 0.380 and 21.032 respectively.

\section{Discussion}

This study aims to identify the factors that will influence the quality of the AIS among SMEs in Sibu, Sarawak. In this case study, the determinants of AIS quality among SMEs in Sibu involve management commitment, knowledge management, user or employees' training and organizational culture.

According to Table 2, KMO values of all variables are greater than 0.60 (Minimum Value). Thus, a sufficient and suitable sample is derived. The value of each variable for Bartlett's Test is also less than 0.05 of the significant level. This also indicates that the data for the FA is appropriate. The values of variables in the two tests show that the data collected from the questionnaire is suitable and advisable in running FA and the results of FA will be useful for the researchers. According to Table 3, the value of coefficient alpha for each variable is greater than 0.60 . To conclude, the 
questionnaire items in this study are reliable. Since the data are appropriate and reliable for FA, the validity of questionnaire has been enhanced.

Since management commitment has the highest Beta value, it makes the largest contribution to this model. According to Table 4, management commitment and user or employees' training possess the sig. values that are less than 0.05 . Hence, H0 should be rejected but $\mathrm{H} 1$ and $\mathrm{H} 3$ should be supported in this study. This also indicates that these two IVs have a positive relationship with the DV (Quality of AIS) at a 5\% significant level. Since the sig. values of knowledge management and organizational culture are greater than $0.05, \mathrm{H} 2$ and $\mathrm{H} 4$ should be rejected and $\mathrm{H} 0$ should be supported. Hence, these two IVs do not have a positive relationship with the DV.

Multicollinearity occurs when two or more IVs in a multiple regression model are highly correlated and leads to inaccurate outcomes of the analysis (Kumar et al., 2013). Generally, there is a potential problem of multicollinearity when the VIF exceeds 10.00 (Hair et al., 2010). Since all values of VIF are not greater than 10.00 , there is no multicollinearity issue in this research.

The value of F-Statistics which is represented in Table 4 indicates that there is a positive relationship between all variables in the regression model. $\mathrm{R}^{2}$ value of 0.380 shows that there is $38 \%$ of the variation in the quality of AIS is explained by management commitment, knowledge management, user or employees' training and organizational culture. In other words, $38 \%$ of the data collected fit the regression model and thus the model is significant.

\section{Contribution}

Firstly, this study provides the related parties such as management, novice users, researchers and auditors a better insight into the implementation of AIS and its quality. Effective AIS will help organization especially SMEs in their business decision making. Next, the study will set a clear direction in devising effective methods in improving the AIS quality especially in Sibu, Sarawak. It is vital to identify the determinants affecting AIS quality in order to implement effective. Moreover, this study provides some data and knowledge on the knowledge niche of AIS especially SMEs in Sibu market. Other researchers can use provided data and information as a stepping stone to dive into AIS niche. Finally, the study will help SMEs especially in Sibu to recognize the determinants that will affect the quality of AIS implementation. The quality of information is critical and has a significant impact on business decision making.

\section{Recommendations for Future Research}

It is recommended for future research or study to apply a larger sample size. Larger sample size will result in better generalization of the population. Future research in other cities or regions in Sarawak can be carried out to derive a better and deeper comprehension of the determinants of AIS quality among SMEs. Other determinants such as organizational structure, system complexity, internal control system and organizational commitment could be considered to add depth to the study. Moreover, researchers can consider both interview and questionnaire to collect data from respondents (Al-Hiyari et al., 2013). Interview will complement the data acquired from questionnaire as interview provides a more detailed information on the determinants from respondents. 


\section{Conclusion}

To encapsulate, management commitment, user or employees' training have a positive relationship with the AIS quality among SMEs in Sibu, Sarawak. On the contrary, knowledge management and organizational culture have a negative relationship towards the quality of AIS. AIS greatly assists the enterprises, investors and other relevant parties to make effective decisions, it is vital to understand the determinants of the system's quality. SME owners should put in commitment and send their relevant staff for training to improve the quality of AIS in Sibu, Sarawak.

\section{References}

Abu-Raqabeh, T. (2018). Accounting Information Systems. Education and Linguistics Research, 4(2):104. DOI: 10.5296/elr.v4i2.14045

Agung, M. (2015). Accounting Information System and Improvement on Financial Reporting. International Journal of Recent Advances in Multidisciplinary Research, 02(11), 950-957.

Aldegis, A. M. (2018). Impact of Accounting Information Systems' Quality on the Relationship between Organizational Culture and Accounting Information in Jordanian Industrial Public Shareholding Companies. International Journal of Academic Research in Accounting, Finance and Management Sciences, 8(1), 70-80.

Algrari, A. Y. \& Ahmed, R. M. (2019, February 8-12). The impact of Accounting Information Systems' Quality on Accounting Information Quality [Paper presentation]. Conference: Reform of Accounting and Auditing Systems- Reality $\&$ Requirements, Kurdistan, Iraq.

Al-Hiyari, A., Al-Mashregy, M. H., Mat, N. K., \& Alekam, J. M. (2013). Factors that Affect Accounting Information System Implementation and Accounting Information Quality: A Survey in University Utara Malaysia. American Journal of Economics, 3(1), 27-31.

Ambarwati, N., Firdaus, M. \& Widaninggar, N. (2020). Success Factors of Accounting Information System in Pt. Kuncimas Niagatama Banyuwangi. Journal of Management and Business Aplication, 3(1), 254-256.

Balasundaram, N. (2009). Factor Analysis: Nature, Mechanism and Uses in Social and Management Science Research. Journal of Cost and Management Accountant XXXVII (2), 15-25.

Bateman, T., \& Snell, S. (2004). Management: The New Competitive Landscape with $C D$ and PowerWeb 6th Edition. McGraw-Hill/Irwin.

Bergant, Z. (2021). Accountancy Information System for Sustainable Future. International Journal of Latest Research in Humanities and Social Science, 4(1), 01-07.

Bong, M. \& Susanto, A. (2018, June 22-24). The Influence of Information Technology on the Quality of Accounting Information System [Paper Presentation]. HPCCT 2018: 2018 2nd High Performance Computing and Cluster Technologies Conference, Beijing, China.

Bougie, R., \& Sekaran, U. (2009). Research Methods for Business: A Skill-building Approach. Wiley. 
Burgess, S. (2002). Information Technology in Small Business: Issues and Challenges. Hershey, PA: Idea Group Publishing.

Campos, E. B., \& Pablos, P. O. (2004). Innovation and learning in the knowledge-based economy: challenges for the firm. International Journal of Technology Management, 27(6/7), 531-533.

Cantrell, M. A. (2011). Demystifying the research process: understanding a descriptive comparative research design. Pediatric Nursing; Pitman, 37(4), 188-189.

Clearly, P. (2017). Introduction to Accounting Information Systems. Taylor \& Francis Group.

Diansari, L. M., Sujana, I. K., Budiasih, I. G., \& Sari, M. M. (2020). User Involvement, Training and Education of the User, Formalization of the Development of Information System and Support of Top Management to the Performance of Udayana University AISs. International Research Journal of Management, IT \& Social Sciences, 7(4), 65-79.

Endraria. (2016). Users Competence and Influence on the Quality of Accounting Information System. Journal of Theoretical and Applied Information Technology, 86(1).

Endraria. (2018). The Effect of Organizational Culture and Discipline on Quality of Accounting Information System In The Financial Management Agency And Asset Regional Government of Regency of Regency, City and West Java Province. International Journal of Humanities and Social Science Invention, 7 (04), 73-77.

Fitrios, R. (2016). Factors That Influence Accounting Information System Implementation And Accounting Information Quality. International Journal of Scientific \& Technology Research, 5(4).

FMT. (2020). Malaysia is ageing, raise retirement age to 65 gradually, says World Bank. Retrieved February 26, 2021, from https://www.freemalaysiatoday.com/category/nation/2020/11/24/malaysia-isageing-raise-retirement-age-to-65-gradually-says-world-bank/

Gillham, B. (2008). Developing a Questionnaire. Continuum.

Guinea, A. O., Kelley, H., \& Hunter, M. G. (2005). Information Systems Effectiveness in Small Businesses: Extending a Singaporean Model in Canada. Journal of Global Information Management (JGIM), 13(3), 55-70.

Hair, J. F., Black, W. C., Babin, B. J., \& Anderson, R. E. (2010). Multivariate Data Analysis Seventh Edition. Pearson Education Limited.

Hall, J. A. (2008). Accounting Information Systems. Cengage Learning.

Hunter, M. G., \& Long, W. A. (2003). Adopting the Entrepreneurial Process in the Study of Information Systems and Small Business. Irm Press.

Kabir, S. M. (2016). Basic Guidelines for Research: An Introductory Approach for All Disciplines First Edition. Chittagong: Book Zone Publication.

Kanakriyah, R. (2016). The Effect of Using Accounting Information Systems on the Quality of Accounting Information According to Users Perspective in Jordan. European Journal of Accounting, Auditing and Finance Research, 4(11), 58-75.

Khlif, H., \& Achek, I. (2017). Gender In Accounting Research: A Review. Managerial Auditing Journal, 32(6), 627-655.

King, W. R. (2009). Knowledge Management and Organizational Learning. Springer US. 
Krahel, J. P., \& Vasarhelyi, M. (2014). AIS as a Facilitator of Accounting Change: Technology, Practice, and Education. Journal of Information Systems, 28(2), 115.

Kumar, M., Talib, S. A., \& Ramayah, T. (2013). Business Research Methods. New York: Oxford University Press.

Louadi, M. E. (2009). The Relationship Among Organization Structure, Information Technology and Information Processing in Small Canadian Firms. Canadian Journal of Administrative Science, 15(2), 99-180.

Meiryani. (2014). Influence of Top Management Support on the Quality of Accounting Information System and Its Impact on the Quality of Accounting Information. Research Journal of Finance and Accounting, 5(11), ISSN 2222-1697.

Mitchell, F., Reid, G. C., \& Smith, J. A. (2000). Information System Development in the Small Firm: The Use of Management Accounting. CIMA Publishing.

Nguyen, H. T., \& Nguyen, A. H. (2020). Determinants of Accounting Information Systems Quality: Empirical Evidence from Vietnam. Academy of Entrepreneurship Journal, 26(2s), 185-198.

Nurhidayati, F., Sensuse, D. I., \& Noprisson, H. (2017, October 23-24). Factors influencing Accounting Information System Implementation [Paper Presentation]. International Conference on Information Technology System and Innovation, Bandung, Indonesia.

Nusa, I. B. (2015). Influence Of Organizational Culture And Structure On Quality Of Accounting Information System. International Journal of Scientific \& Technology Research, 4(5), ISSN 2277-8616.

Onaolapo, A. A., \& Odetayo, T. A. (2012). Effect of Accounting Information System on Organisational Effectiveness: A Case Study of Selected Construction Companies in Ibadan, Nigeria. American Journal of Business and Management, 1(4), 183-189.

Osborne, J. W., \& Fitzpatrick, D. C. (2012). Replication Analysis in Exploratory Factor Analysis: What it is and why it makes your analysis better. A Peer-Reviewed Electronic Journal, 17(15), ISSN 1531-7714.

Polit, D. F., \& Beck, C. T. (2012). Nursing Research: Generating and Assessing Evidence for Nursing Practice. Wolters Kluwer.

Pollard, C. E., \& Hayne, S. C. (1998). The Changing Face of Information System Issues in Small Firms. International Small Business Journal, 16(3), 70-87.

Rahayu, S. K. (2012). The Factors That Support the Implementation of Accounting Information System: A survey in Bandung and Jakarta's Taxpayer Offices. Journal of Global Management, 4(1).

Rapina. (2014). Factors Influencing The Quality of Accounting Information System and Its Implications on The Quality of Accounting Information. Research Journal of Finance and Accounting, 5(2), ISSN 2222-1697.

Romney, M. B., \& Steinbart, P. J. (2015). Accounting Information Systems, 13th Edition. Pearson Education Limited.

Rosa, D. \& Purfini, A. P. (2019). Analysis Effect Quality of Accounting Information Systems to SupportCompany Performance. IOP Conference Series: Materials Science and Engineering, 662(3), doi:10.1088/1757-899X/662/3/032015

Rue, L. W., \& Byars, L. L. (2007). Management : skills and application 12th Edition. McGraw Hill Education. 
Submitted: 5 April $2021 \quad$ Accepted: 24 May $2021 \quad$ Published: 30 June 2021

Rutberg, S., \& Bouikidis, C. D. (2018). Focusing on the Fundamentals: A Simplistic Differentiation Between Qualitative and Quantitative Research. Nephrology Nursing Journal, 45(2), 209-214.

Sedera, D., \& Gable, G. G. (2010). Knowledge Management Competence for Enterprise System Success. Journal of Strategic Information Systems, 19(4), 296-306.

Sekaran, U., \& Bougie, R. (2016). Research Methods for Business: A Skill-Building Approach Seventh Edition. Chichester: John Wiley \& Sons Ltd.

Shagari, S. L., Abdullah, A., \& Saat, R. M. (2017). Accounting Information Systems Effectiveness: Evidence from the Nigerian Banking Sector. Interdisciplinary Journal of Information, Knowledge, and Management, 12, 309-335.

Ta, Q. B., \& Nguyen, T. T. (2020). Impact of factors on the quality of accounting information system in civil engineering construction enterprises. Management Science Letters 10(13), 2985-2992.

Tewksbury, R. (2009). Qualitative versus Quantitative Methods: Understanding Why Qualitative Methods are Superior for Criminology and Criminal Justice. Journal of Theoretical and Philosophical Criminology, 1(1), 38-58.

Thuan, L. D. (2019). Assessing Some Factors Influence Quality of Accounting Information System - In Vietnam. Journal of Science and Technology, 37(1). https://doi.org/10.46242 /jst-iuh.v37i01.322

Tilahun, M. (2019). A Review on Determinants of Accounting Information System Adoption. Science Journal of Business and Management, 7(1), 17-22.

Turban, E., Leidner, D., McLean, E., \& Wetherbe, J. (2004). Information Technology for Management: Transforming Organizations in the Digital Economy. Wiley.

Ursachi, G., Horodnic, I. A., \& Zait, A. (2015). How reliable are measurement scales? External factors with indirect influence on reliability estimators. Procedia Economics and Finance, 20, $679-686$.

Wisna, N. (2018). Factors Affecting The Quality Of Accounting Information. International Journal of Scientific \& Technology Research, 7(4), ISSN 22778616.

Yong, A. G., \& Pearce, S. (2013). A Beginner's Guide to Factor Analysis: Focusing on Exploratory Factor Analysis. Tutorials in Quantitative Methods for Psychology, 9(2), 79-94.

Zikmund, W. G., Babin, B. J., Carr, J. C., \& Griffin, M. (2011). Business Research Method 8th edition. Cengage Learning. 